\title{
DEPTH OF POLYMERIZATION OF A NEW NANOCOMPOSITE ACCORDING TO DIFFERENT EXPOSURE TIMES AND SHADES
}

J.L. Lui, C.L. Chan, K.T. Yap. Depth of polymerization of a new nanocomposite according to different exposure times and shades. Annal Dent Univ Malaya 2006; 13: 6-11.

\begin{abstract}
The aim of the study was to determine the depth of cure of a new nanocomposite when exposed to different curing times and also when different shades were polymerized. The nanocomposite, Filtek Supreme (3M ESPE), was packed into 96 plastic cylindrical moulds measuring $4 \mathrm{~mm}$ in internal diameter and $8 \mathrm{~mm}$ in length and then polymerized using a conventional quartz-tungsten-halogen light curing unit. The first part of the study involved curing 16 samples each of A2 shade of the nanocomposite at exposure times of $20 \mathrm{~s}, 40 \mathrm{~s}, 60 \mathrm{~s}$ and $120 \mathrm{~s}$. For the second part, a similar number of samples of the dentinal opacity shades of A2, B3 and $\mathrm{A} 4$ of the nanocomposite were polymerized at a constant exposure time of 40s. The depth of polymerization of the nanocomposite in each sample was measured using a digimatic indicator. Curing depths were found to increase significantly $(\mathrm{P}<0.05)$ with longer exposure time $(20 \mathrm{~s}<40 \mathrm{~s}<60 \mathrm{~s}<120 \mathrm{~s})$ and decrease significantly with darker shades (A2 $>$ B3 > A4).
\end{abstract}

Key words: depth of polymerization, nanocomposite, exposure time, shade.

\section{INTRODUCTION}

Visible light-curing composite resins are one of the most popular dental materials nowadays and they are being extensively used in dentistry for various restorative and preventive procedures. Following their introduction in the 1970s the visible light-curing composites have exhibited numerous advantages over the self-curing varieties; these include adequate working time, on-command set, less porosity and better colour stability. The first visible light-curing sources are based on emission from quartz-tungstenhalogen (QTH) curing devices which are still popularly used today. Recent developments include the argon-ion laser, plasma arc curing device, high intensity QTH light and blue light-emitting diode which have been demonstrated to reduce the exposure time whilst providing a cure similar to the conventional QTH device(1).

Since their introduction, there has been concern about the depth of cure of visible light-activated
Original Article

J. L. Lui', C. L. Chan ${ }^{2}$, K. T. Yap

IProfessor
${ }^{2}$ Dental Student
Department of Conservative Dentistry
Faculty of Dentistry
University of Malaya
50603 Kuala Lumpur
Malaysia
Corresponding author - Lui Joo Loon

composite restorations. The pattern of setting for such light-curing composites is determined by the fact that polymerization is first achieved and is more complete at the surface layers where the light intensity is the greatest(2). The intensity of light decreases greatly as light passes through the bulk of the restorative material; thus reducing the potential for curing. This decrement in cure from the top surface inward is known as 'limited depth of cure' and it has certain clinical implications on the physical and biological properties of the restoration. With such inadequate depth of cure, the longevity of visible light-cured composite restorations will be reduced(3). Besides physical and mechanical failures, the inadequately polymerized composite will also give rise to clinical problems such as loss of marginal adaptation and poor bonding to tooth structure; resulting in subsequent microleakage, sensitivity, greater stain uptake and secondary caries. In extreme cases, loss of the restoration may also occur (3-5).

There are numerous factors which can influence the polymerization depth of visible light-cured composite restorations. Over the years, studies have been conducted to determine the influence of exposure time from a light source on the depth of cure of composites. This factor has much clinical relevance as the length of exposure time is one of the factors which is controllable by the operator. Besides exposure time, the shade of the composite resin has also been shown to have considerable influence on the depth of cure.

Various types of visible light-curing composite resins had been developed and introduced to the dental profession. Recently, with the development of nanotechnology, nanocomposites had also been introduced to dentistry. This investigation was therefore conducted to determine the depth of cure of a new nanocomposite in relation to the duration 
of light exposure and with the use of different shades of the nanocomposite.

\section{MATERIALS AND METHOD}

Ninety-six plastic hollow cylinders were obtained by cutting from a long white plastic water filter tube which had an internal diameter of $4 \mathrm{~mm}$. Each tube was then smoothened at both the cut ends using a grinder (Rotopol, Struers, Copenhagen, Denmark) to accurately obtain a hollow cylinder measuring 8 $\mathrm{mm}$ in length. One end was then sealed by means of superglue to a small piece of black cardboard (Figure 1). The 96 prepared plastic cylinders were then divided into six groups of 16 specimens each.

The new nanocomposite material of shade A2 in dentinal opacity (Filtek ${ }^{\mathrm{TM}}$ Supreme, $3 \mathrm{M}$ ESPE, St Paul, MN 55144 - 1000, USA) was ejected from the syringe and firmly packed into the plastic cylinder using suitable plastic instruments. A matrix strip (Ruwa Matrix Strips, Associated Dental Products Ltd, Purton, Swindon, Wiltshire SN5 9HT, UK) was placed on top of the packed nanocomposite and pressed with a glass slide. Excess composite material was removed. The power density of a conventional QTH light-curing unit (Coltolux 3, model C7911, Coltene $^{\circledR}$, Whaledent Inc, NJ 07430, USA) was first measured with a radiometer (Demetron Kerr, Danbury, CT 06810-4131, USA) and determined to be in the range of $460-480 \mathrm{mw} / \mathrm{cm}^{2}$. The light-curing tip of the unit was then placed against the matrix strip and the nanocomposite cured according to the different selected exposure times of $20 \mathrm{~s}, 40 \mathrm{~s}, 60 \mathrm{~s}$ and 120s. Sixteen specimens of the dentinal opacity shade A2 were cured for each exposure time. The exposure time of 40 s acted as the control as this was recommended by most manufacturers. Besides shade A2, specimens comprising dentinal opacity shades B3 and A4 were similarly cured but at a constant exposure time of 40 s. Sixteen nanocomposite specimens were thus obtained for each shade with the lightest shade A2 acting as the control.

Immediately following polymerization, the closed end of each specimen was exposed by removing the cardboard. Depth of cure of the nanocomposite was then determined by using a digimatic indicator (Mitutoyo, Minato-Ku, Tokyo 108, Japan). The digimatic indicator, a high-accuracy displacementmeasuring instrument, has a counter unit carrying a spindle and a main display unit (Figure 2). Attached to the end of the spindle is a hardened cylindrical stainless steel gauge with a diameter of $0.5 \mathrm{~mm}$. The tip of the gauge was first placed directly in contact with the indicator platform and the reading on the digital display was adjusted to zero. The spindle with its attached gauge was then lifted and the plastic tube was placed with the polymerized nanocomposite end in contact with the platform beneath the lifted gauge. The gauge was lowered into the unpolymerized nanocomposite at the now exposed end (Figure 3). A constant force of $1.77 \mathrm{~N}$ was applied by the digimatic indicator for $15 \mathrm{~s}$. The depth of cure was determined by the amount of displacement as counted by a photoelectrical linear encoder detector unit which was displayed on the digital display. The data was

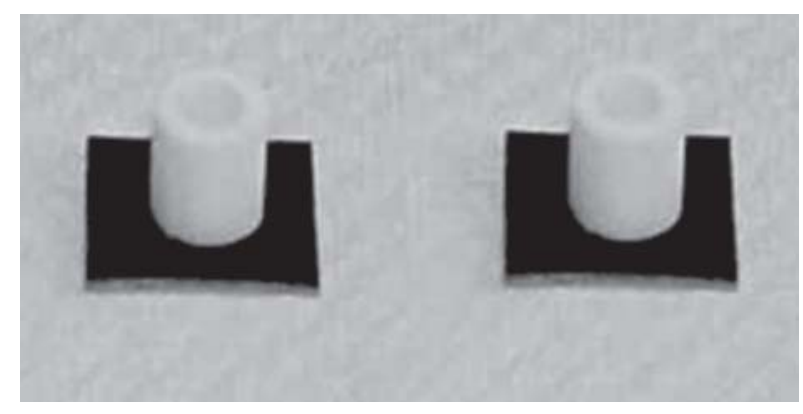

Figure 1: Two $8 \mathrm{~mm}$ x $4 \mathrm{~mm}$ plastic cylinder tubes with one end closed by black cardboard using superglue.

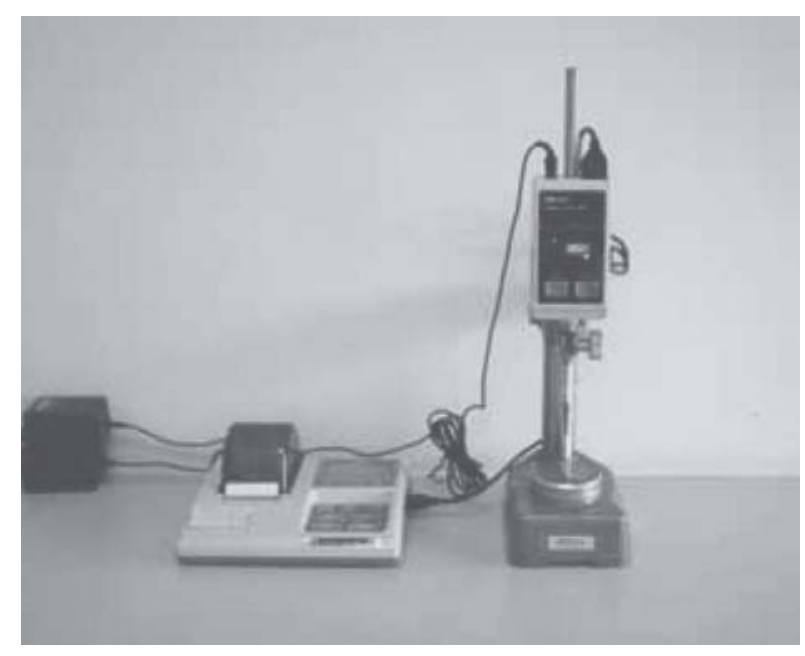

Figure 2: The Mitutoyo digimatic indicator.

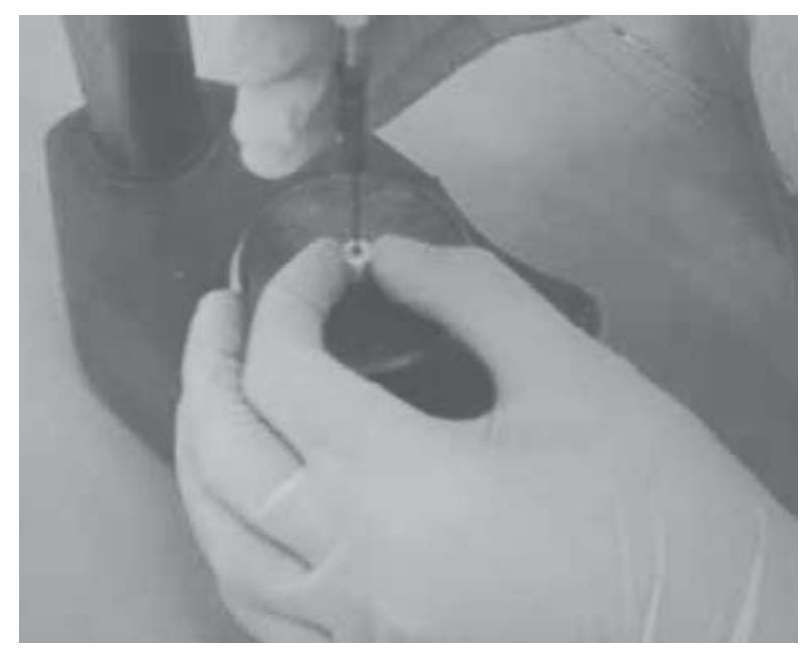

Figure 3: Measurement of depth of cure using the digimatic indicator. 
then transferred to a digimatic data processor via a data output port. For each specimen, the depth of cure (the height of a cylinder of polymerized nanocomposite) was measured at five random positions.

Statistical analysis was conducted on the data collected using one way ANOVA and post-hoc Tukey HSD (honestly significant difference) test through the SPSS computer programme.

\section{RESULTS}

\section{Different Exposure Times}

The mean depth of cure according to different exposure times is presented in Table 1. The one way ANOVA showed that there were significant differences in the depths of cure for different exposure times $(\mathrm{P}<0.05)$. Post-hoc Tukey HSD test comparisons revealed significant differences between each group of specimens for each exposure time. The results showed that it was possible to achieve greater depths of polymerization by increasing the exposure time.

Table 1. Mean depth of cure $(\mathrm{mm})$ for Filtek Supreme with different exposure times

\begin{tabular}{ccc}
\hline $\begin{array}{c}\text { Exposure } \\
\text { Time(s) }\end{array}$ & $\begin{array}{c}\text { Depth of Cure } \\
(\mathrm{mm})\end{array}$ & $\begin{array}{c}\text { Standard } \\
\text { Deviation }\end{array}$ \\
\hline 20 & 3.856 & 0.035 \\
40 & 4.520 & 0.059 \\
60 & 4.760 & 0.050 \\
120 & 5.397 & 0.143 \\
\hline
\end{tabular}

\section{Different Shades}

The mean depth of cure according to different shades is presented in Table 2. The one way ANOVA revealed significant differences in the depths of cure for the different shades $(\mathrm{P}<0.05)$. Post-hoc Tukey HSD test comparisons showed significant differences between each group of different shade. The results revealed that the depth of polymerization was reduced in the darker shade nanocomposite.

Table 2. Mean depth of cure $(\mathrm{mm})$ for Filtek Supreme with different shades

\begin{tabular}{ccc}
\hline $\begin{array}{c}\text { Shade } \\
\text { (Vita guide) }\end{array}$ & $\begin{array}{c}\text { Depth of cure } \\
(\mathrm{mm})\end{array}$ & $\begin{array}{c}\text { Standard } \\
\text { Deviation }\end{array}$ \\
\hline A2 & 4.520 & 0.059 \\
B3 & 4.016 & 0.056 \\
A4 & 3.692 & 0.049 \\
\hline
\end{tabular}

\section{DISCUSSION}

This study was conducted to evaluate the depth of polymerization of a new nanocomposite according to different exposure times and shades. A newlydeveloped nanocomposite Filtek ${ }^{\mathrm{TM}}$ Supreme which was introduced very recently in 2002 by $3 \mathrm{M}$ ESPE was selected for the study as there were relatively few investigations conducted on it. Depth of cure in any visible light-activated composite restoration is of considerable importance as unpolymerized material at the base of a restoration can give rise to serious clinical implications which also holds true for the nanocomposite. Nanocomposites consist of particle sizes much smaller than the microfills; with their sizes below the wavelengths of visible light. With the introduction to dentistry of such nanotechnology, it had been reported that the new nanocomposite material possessed top quality features such as high translucency, high polish and physical and wear resistance equivalent to those of hybrid composites(6).

There are various methods to determine the depth of cure of resin composites. In the direct method, the degree of conversion of a composite can be determined by Fourier Transform Infrared Analysis (FTIR) (7-10), Raman and FT-Raman spectroscopy $(11,12)$ and differential thermal analysis (DTA) $(13,14)$. Raman spectroscopy has limited use due to its poorer sensitivity while FTIR is time consuming and may be imprecise when the curing of the composite specimen is disproportionate. DTA appears to provide a more meaningful and reproducible result for the direct determination of the degree of conversion of composite material(14).

In the indirect method, the depth of cure can be determined by measuring the hardness or microhardness of the polymerized material $(5,15-17)$, detecting the changes in translucency between cured and uncured material using an optical microscope $(18,19)$, scraping of the soft unpolymerized resin from the bottom of a light-activated sample and then determining the depth of cure by measuring the residual thickness $(11,18)$ and nuclear magnetic resonance microimaging to produce threedimensional images of the polymerized sample (20, 21).

The method used in this study was a refinement of the scraping technique where a needle penetrometer was used to penetrate the unpolymerised nanocomposite to measure the thickness of the cured material(22). Both the scraping and the penetrometer methods similarly measured the height of a cylinder of cured composite material but the penetrometer provided a more consistent result due to the constant applied force. This method was chosen for the present study because it was simple to perform, reproducible and extensively used by other researchers $(3,21,22)$. It 
also correlated well with the optical method though there was a tendency to overestimate depth of cure compared to microhardness testing or degree of conversion analysis(18).

The amount of exposure time to light is one of the most important operator-dependent factors governing the polymerization of light activatedcomposites. When the light intensity is sufficient to activate the photoinitiator in the restorative material, the duration of exposure to light is thereby the next rate limiting step in the polymerization process(23). In the present study, the depth of cure of the nanocomposite was found to increase with a greater duration of exposure time. This was in agreement with other studies conducted on composite resins regarding the influence of exposure times on their depth of cure $(19,24)$.

From the results, the nanocomposite on exposure for 20 s to light exhibited the lowest depth of cure when compared to the recommended $40 \mathrm{~s}$ exposure (control) which gave a $17.2 \%$ significant increase in curing depth. Increasing the exposure time from $40 \mathrm{~s}$ to $60 \mathrm{~s}$ resulted in a further $5.32 \%$ increase in curing depth. The greatest depth of cure was achieved at 120 s exposure time (Table 1). Most studies found that 20 s curing time was insufficient to achieve an adequately cured resin composite; particularly in depths of $1 \mathrm{~mm}$ or greater(25). A mean curing depth of $3.856 \mathrm{~mm}$ was achieved with an exposure time of 20s; however, the new nanocomposite was the material used in the present study and thus could not be compared to those using microfilled and hybrid composites. For most commercially available composites, researchers had recommended a curing time of $40 \mathrm{~s}(26)$ but there were others $(27,28)$ who reckoned that 60 s exposure should be indicated to produce a uniform cure and to attain acceptable hardness for composite restorations of varying thicknesses.

Increasing the exposure time to $120 \mathrm{~s}$ in this study produced the maximum depth of cure for the new nanocomposite. However, it was felt that $120 \mathrm{~s}$ was too long and not clinically feasible as this would result in greater chairside time. Furthermore, it was reported that the longer exposure time would result in greater temperature rise(29). It was also found that the increase in depth of cure with longer exposure time was followed by a high increase in temperature which could be quite damaging to the pulp(30).

The shade of the composite resin had always been regarded as a factor which could significantly affect the depth of cure. The results of this study on the new nanocomposite showed significant decrease in depth of cure as the shade became darker. The lightest shade (A2) showed a depth of cure of $4.52 \mathrm{~mm}$ which was reduced to $4.02 \mathrm{~mm}$ for shade B3 and $3.69 \mathrm{~mm}$ for the darkest shade (A4) when similarly exposed to the recommended curing time of $40 \mathrm{~s}$. Thus, the depth of cure of shade B3 was reduced by $11.14 \%$ compared to A2 whilst the depth of cure of A4 was $18.31 \%$ less than that of A2 and $8.07 \%$ less than that of B3. This finding for the new nanocomposite was in agreement with other studies conducted on various composite resins(3133).

It had been reported that the darker shades exhibited significantly reduced depth of cure as a result of greater light absorption by pigments in darker shade composite resins(32). It was further reported that the absorption and scattering of light by the filler particles in the different shades of composite resin controlled the attenuation of light whereby the reduction in light intensity with respect to its original intensity was directly related to the transmission coefficient of the composite resin. Darker shades had lower transmission coefficient values compared to lighter shades and therefore had poorer light transmittance into deeper layers(34). Other researchers had also found that there was good correlation between the transmission coefficient and the cure depth for different shades of composite resins(35). This had therefore given rise to the consensus that prolonged exposure time was necessary for darker shades to achieve an adequate cure compared to lighter shades.

This study was conducted in vitro. In the actual clinical situation, various other factors such as the accessibility to the light source, size, direction and angulation of the light guide tip and design and position of the cavity can result in a depth of cure obtained clinically less than that achieved under more ideal laboratory conditions.

\section{CONCLUSIONS}

Within the limitations of this study, the following conclusions could be drawn:

1. Increased exposure time to curing light resulted in greater depths of cure of the nanocomposite.

2. Lighter shades of the nanocomposite exhibited higher curing depths than the darker shades at a similar exposure time.

\section{REFERENCES}

1. Rueggeberg FA, Engle JW, Mattenburg DJ. Polymerization depths of contemporary lightcuring units using microhardness. J Esthet Dent 2000; $12: 340-9$.

2. Baharav H, Abraham D, Cardash HS, Helft M. Effect of exposure time on the depth of polymerization of visible light-cured composite resin. J Oral Rehabil 1988; 15: 167-72. 
3. Shortall AC, Wilson HJ, Harrington E. Depth of cure of radiation-activated composite restoratives - influence of shade and opacity. J Oral Rehabil 1995; 22: 337-42.

4. Pilo R, Oelgiesser D, Cardash HS. A survey of output intensity and potential for depth of cure among light curing units in clinical use. J Dent 1999; 27: 235-41

5. Yap AUJ. Effectiveness of polymerization in composite restoratives claiming bulk placement: Impact of cavity depth and exposure time. Oper Dent 2000; 25: 113-20.

6. Mitra SB, Wu D, Holmes BN. An application of nanotechnology in advanced dental material. J Am Dent Assoc 2003; 134: 1382-90.

7. Ruyter IE, Oysaed H. Conversion in different depths of UV and visible light activated composite material. Acta Odontol Scand 1982; 40: 179-92.

8. Ferracane JL, Greener EH. Fourier Transform Infrared Analysis of degree of polymerization in unfilled resins - Methods comparison. J Dent Res 1984; 63: 1093-95.

9. Eliades GC, Vougiouklakis GJ, Caputo AA. Degree of double bond conversion in light cured composite. Dent Mater 1987; 3: 19-25.

10. Rueggeberg FA, Hashinger DT, Fairhurst CW. Calibration of FTIR conversion analysis of contemporary dental resin composites. Dent Mater 1990; 6: 241-9.

11. Yearn JA. Factors affecting cure of visible light activated composite. Int Dent J 1985; 35: 21825 .

12. Shin WS, Li XF, Schwartz B, Wunder SL, Baran GR. Determination of the degree of cure of dental resins using Raman and FT Raman spectroscopy. Dent Mater 1993; 9: 317-24.

13. McCabe JF. Cure performance of light-activated composites by differential thermal analysis (DTA). Dent Mater 1985; 1: 231-4.

14. Imazato S, McCabe JF, Tarumi H, Ehara A, Ebisu S. Degree of conversion of composites measured by DTA and FTIR. Dent Mater 2001; 17: $178-83$.

15. Ota K, Kopel HM, Nakamura RM. Effect of light exposure time on the depth of curing in various composite resin systems. Pediatr Dent 1985; 7: 19-22.
16. Harrington E, Wilson HJ, Shortall AC. Lightactivated restorative materials: a method of determining effective radiation times. J Oral Rehabil 1996; 23: 210-8.

17. Obini AC, Sinhoreti MAC, Correr-Sobrinho L, Goes MF, Consani S. Evaluation of depth of cure and Knoop hardness in a dental composite photo-activated using different methods. Braz Dent J 2004; 15: 199-203.

18. Dewald JP, Ferracane JL. A comparison of four modes of evaluating depth of cure of lightactivated composites. J Dent Res 1987; 66: 72730 .

19. Baharav H, Abraham D, Cardash HS, Helft M. Effect of exposure time on the depth of polymerization of visible light-cured composite resin. J Oral Rehabil 1988; 15: 167-72.

20. Lloyd CH, Scrimgeour SN, Chudek JA, et al. Determination of the depth of cure for VLC composites by nuclear magnetic resonance microimaging. Dent Mater 1994; 10: 128-33.

21. Lloyd CH, Scrimgeour SN, Chudek JA, Mackay RL, Hunter G. The application of magnetic resonance microimaging to the visible light curing of dental resins. Part 2. Dynamic imaging by the FLASH-MOVIE pulse sequence. Dent Mater 2001; 17: 170-7.

22. Lui JL. Depth of composite polymerization within simulated root canals using lighttransmitting posts. Oper Dent 1994; 19: 165-8.

23. Caughman WF, Rueggeberg FA, Curtis JW. Clinical guidelines for photocuring restorative resins. J Am Dent Assoc 1995; 126: 1280-6.

24. Swartz ML, Phillips RW, Rhodes B. Visible light-activated resins - depth of cure. J Am Dent Assoc 1983; 106: 634-8.

25. Rueggeberg FA, Caughman WF, Curtis JW. Effect of light intensity and exposure duration on cure of resin composite. Oper Dent 1994; 19 : 26-32.

26. Atmadja G, Bryant RW. Some factors influencing the depth of cure of visible light-activated composite resins. Aust Dent J 1990; 35: 213-8.

27. Rueggeberg FA, Caughman WF, Curtis JW, Davis HC. A predictive model for the polymerization of photo-activated resin composites. Int J Prostho 1994; 7: 159-66. 
28. Kazuo O, Kikuchi S, Kopel HM, Thanos CE, Nakamura RM. Effect of light exposure time on the depth of curing in various composite resin systems. Pediatr Dent 1985; 7: 19-22.

29. Shortall AC, Harrington E. Temperature rise during polymerization of light-activated resin composites. J Oral Rehabil 1988; 25: 908-13.

30. Hansen EK, Asmussen E. Correlation between depth of cure and temperature rise of a lightactivated resin. Scand J Dent Res 1993; 101: 177-9.

31. Ferracane JL, Aday P, Matsumoto H, Maker VA. Relationship between shade and depth of cure for light-activated dental composite resins. Dent Mater 1986; 2: 80-4.
32. Takamizu M, Moore BK, Setcos JC, Philips RW. Efficacy of visible light generators with changes in voltage. Oper Dent 1988; 13: 173-80.

33. Tanoue N, Koishi Y, Matsumara H, Atsuta M. Curing depth of different shades of photoactivated prosthetic composite material. J Oral Rehabil 2001; 28: 618-23.

34. Tirtha R, Fan PL, Dennison JB, Powers JM. In vitro depth of cure of photo-activated composites. J Dent Res 1982; 61: 1184-7.

35. Kawaguchi M, Fukushima T, Miyazaki K. The relationship between cure depth and transmission coefficient of visible light-activated resin composites. J Dent Res 1994; 73: 516-21. 